\title{
ANÁLISE MICROBIOLÓGICA E FÍSICO-QUÍMICA DE LEITE CRU COMERCIALIZADO INFORMALMENTE NO MUNICÍPIO DE IBIRAPUÃ-BA
}

\section{MICROBIOLOGICAL AND PHYSICOCHEMICAL ANALYSIS RAW MILK MARKETED INFORMALLY IN IBIRAPUÃ CITY, BAHIA, BRAZIL}

\author{
Caroline Santos de Sousa ${ }^{1}$ \\ Licenciada em Ciências Biológicas pela Universidade do Estado da Bahia (UNEB), \\ Campus X, Av. Kaikan, s/n - Universitário. Teixeira de Freitas-BA. CEP: 45.992-294 \\ https://orcid.org/0000-0002-6358-5160 \\ carolinesantossousa2014@hotmail.com

\section{Gisele Oliveira Pinheiro de Souza ${ }^{1}$} \\ Licenciada em Ciências Biológicas pela Universidade do Estado da Bahia (UNEB), \\ Campus X, Av. Kaikan, s/n - Universitário. Teixeira de Freitas-BA. CEP: 45.992-294 \\ https://orcid.org/0000-0002-1548-0030 \\ gisele.p5@hotmail.com
}

\section{Tayna de Matos Alcântara ${ }^{1}$}

Licenciada em Ciências Biológicas pela Universidade do Estado da Bahia (UNEB), Campus X, Av. Kaikan, s/n - Universitário. Teixeira de Freitas-BA. CEP: 45.992-294 https://orcid.org/0000-0002-6028-4477

tayna_allves@hotmail.com

\section{Prof. Dr. Jorge Luiz Fortuna ${ }^{2}$}

Universidade do Estado da Bahia (UNEB), Campus X, Laboratório de Microbiologia, Av. Kaikan, s/n - Universitário. Teixeira de Freitas-BA. CEP: 45.992-294

https://orcid.org/0000-0001-7996-837X jfortuna@uneb.br

1 Participação na formatação e elaboração do artigo: Redação; Metodologia; Investigação; Análise e Discussão dos Resultados.

Participação na formatação e elaboração do artigo: Recursos; Revisão; Supervisão; Orientação; Revisão da versão final.

\section{RESUMO}

O leite possui muitas riquezas nutricionais, sendo considerado um dos alimentos mais completos para os seres humanos, principalmente nos primeiros anos de vida. Por apresentar um elevado valor nutritivo torna-se excelente matriz favorável à proliferação de microrganismos, inclusive patogênicos. O objetivo geral deste estudo foi avaliar a qualidade microbiológica e físico-química do leite cru comercializado na cidade de Ibirapuã-BA. Foram analisadas 12 amostras de leite cru, pertencentes a três pontos distintos (fazenda, residência e ambulante) sendo todas as amostras devidamente 
acondicionadas em caixas isotérmicas com gelo e transportadas ao Laboratório de Microbiologia do Campus $X$ da Universidade do Estado da Bahia (UNEB). Utilizou-se a técnica de Número Mais Provável (NMP) para a enumeração de coliformes totais e termotolerantes, além, de testes bioquímicos para a identificação de Escherichia coli e Staphylococcus coagulase positivo e, por fim, características físico-químicas do leite cru: $\mathrm{pH}$, densidade, acidez Dornic, teste do alizarol e presença de amido. Nas análises microbiológicas, as 12 (100\%) amostras de leite cru apresentaram contaminação acima do padrão e nas análises físicoquímicas das 12 (100\%) amostras, apenas uma $(8,33 \%)$ amostra se encontrou em desacordo com as normativas, no requisito densidade. O leite cru comercializado, de forma clandestina, no município de Ibirapuã-BA apresenta elevados índices de contaminação por microrganismos patogênicos, tais como coliformes termotolerantes e estafilococos, comprometendo a inocuidade e, portanto, representando risco à saúde do consumidor.

Palavras-chave: Clandestino. Coliformes. Contaminação.

\section{ABSTRACT}

The milk has many nutritional riches, considered one of the most complete food for humans, especially in the first years of life. Due to its high nutritional value, it is an excellent matrix favorable to the proliferation of microorganisms, including pathogens. The aim of this study was to evaluate the microbiological and physicalchemical quality of raw milk sold in the city of Ibirapuã-BA. Twelve samples of raw milk were analyzed, belonging to three different points (farm, residence and hawker) and all samples were properly packed in isothermal boxes with ice and transported to the Microbiology Laboratory of Campus $X$ of the State University of Bahia (UNEB). The Most Probable Number (MPN) technique was used for the enumeration of total and thermotolerant coliforms, in addition to biochemical tests for the identification of Escherichia coli and positive coagulase Staphylococcus and, finally, physical-chemical characteristics of raw milk: $\mathrm{pH}$, density, Dornic acidity, alizarol test and presence of starch. In microbiological analyzes, the $12(100 \%)$ samples of raw milk showed contamination above the standard and in the physicalchemical analyzes of the $12(100 \%)$ samples, only one (8.33\%) sample was found to be in disagreement with the regulations, in the density requirement. Raw milk marketed, clandestinely, in the city of Ibirapuã-BA has high levels of contamination by pathogenic microorganisms, such as thermotolerant coliforms and staphylococci, compromising innocuousness and, therefore, representing a risk to consumer health.

Keywords: Clandestine. Coliforms. Contamination.

\section{INTRODUÇÃO}

$\mathrm{Na}$ atualidade a sociedade se apresenta em uma rede de desemprego aliada a um contexto de capitalismo, portanto à falta de orientação e a necessidade de uma fonte de renda não assalariada engajou um novo quadro tanto no meio urbano quanto no rural, no qual a experiência de trabalho como vendedor informal acabou se tornando uma forma de emprego (TELLES, 2012). Essa práxis relaciona-se com o cotidiano do comerciante, onde, o próprio, tenta buscar formas de garantir sua renda, mesmo esta sendo considerada uma atividade contingente, já que são marcadas pela falta de legalização, instabilidade e pela inconstância. Nesta perspectiva, atuam os vendedores ambulantes (SILVA, 2011).

O consumo de leite informal se justifica pela baixa renda familiar e baixo grau de 
instrução da população, tendo os aspectos higiênico-sanitários pouca influência sobre a decisão de compra (FERRÃO et al., 2003). Além disso, tem a crença de que é um produto mais forte, puro e nutritivo, que apresenta um menor preço e muitas vezes com a facilidade de ser entregue em casa.

A maioria dos consumidores de leite cru não considera sua ingestão um risco à saúde.

O comércio do leite informal, para o pequeno produtor, é uma alternativa importante de comercialização, que encontra uma demanda bem estabelecida no país (NERO et al., 2004). Entretanto, essa forma de comercialização, além de proibida por lei (BRASIL, 2017) gera problemas como concorrência desleal com laticínios recolhedores de impostos e elevação dos riscos à saúde do consumidor.

Mediante ao fato de que esses indivíduos "autônomos" trabalham de forma ilícita e não possuem obrigação de implementar programas de controle de qualidade e que visem condições higiênico-sanitárias satisfatórias, além de não serem submetidos à fiscalização por parte das autoridades oficiais, já que não passam em nenhum tipo de teste que verifique as condições higiênico-sanitárias em que são produzidos o leite, aumenta-se a relevância social na busca por analisar a relação de possíveis toxinfecções intestinais com a venda ilegal deste produto. Entretanto para garantir sua fonte de renda, esses ambulantes optam pela comercialização do leite mesmo de forma proibida.

A contaminação microbiana no leite cru comercializado por vendedores ambulantes pode ocorrer da manipulação para a retirada do leite até 0 armazenamento, e isso pode refletir na qualidade higiênico-sanitária do produto. Sendo que esse fato pode acontecer em qualquer etapa do processo, até no transporte, refrigeração e distribuição, levando muitas vezes a um produto contaminado (ROSA; QUEIROZ, 2007).

Os coliformes termotolerantes, mais especificamente Escherichia coli, são indicadores de contaminação fecal e do risco da presença de microrganismos patogênicos, que podem causar toxinfecções. Já os coliformes totais são indicadores de condições higiênicosanitárias precárias, mas nem sempre de contaminação fecal. Segundo Franco e Landgraf (2005), os microrganismos indicadores são grupos ou espécies que, quando presentes em um alimento, podem fornecer informações sobre a ocorrência de contaminação fecal, sobre a provável presença de patógenos ou sobre a deterioração potencial de um alimento, além de poder indicar condições sanitárias inadequadas durante o processamento, produção ou armazenamento.

A importância da constatação de Staphylococcus aureus em alimentos vincula-se às toxinas produzidas por esses 
microrganismos, as quais podem trazer sérios danos à saúde do consumidor (OLIVEIRA; CARUSO, 1996).

Ibirapuã é uma cidade localizada no Extremo Sul da Bahia. O município se estende por $787.700 \mathrm{~km}^{2}$ e conta com 7.956 habitantes de acordo com o último censo (IBGE, 2020). Sendo vizinha dos municípios de Serra dos Aimorés-MG, Teixeira de Freitas-BA e Lajedão-BA. lbirapuã situa-se a trinta quilômetros a Nordeste de Nanuque, a maior cidade nos arredores (IBIRAPUÃ, 2020). Em volta do município se encontram algumas áreas rurais com fazendas e sítios que produzem leite.

Sendo assim, o objetivo geral deste estudo foi avaliar a qualidade microbiológica e físico-química do leite cru comercializado informalmente na cidade de Ibirapuã-BA.

\section{METODOLOGIA}

Foram realizadas quatro coletas de amostras de leite cru, comercializados de forma informal ou clandestina no município de Ibirapuã-BA, em temperatura ambiente (sem refrigeração), de três locais distintos: uma fazenda (na área rural); uma residência (na área urbana) e um ambulante fixo (também na área urbana), totalizando 12 amostras. As amostras foram coletadas no período de setembro a dezembro de 2019, sempre pela manhã.

Todas as amostras foram armazenadas em frascos de vidro, previamente esterilizados em autoclave $\left(121^{\circ} \mathrm{C} / 15 \mathrm{~min}\right)$. Sempre foi coletado $1.000 \mathrm{~mL}$ de cada amostra de leite cru. Após a coleta todas as amostras foram devidamente acondicionadas em caixas isotérmicas contendo gelo e transportadas imediatamente ao Laboratório de Microbiologia da Universidade do Estado da Bahia (UNEB), Campus X, onde foram realizadas as análises microbiológicas e físico-químicas.

Para as análises microbiológicas foram realizadas enumeração de coliformes totais e termotolerantes e contagem de Staphylococcus aureus coagulase positiva, seguindo as metodologias de Silva et al. (2017). Também foram realizados testes bioquímicos para a identificação de bactérias da família Enterobacteriaceae.

Após a homogeneização da amostra do leite cru foi transferido, com o auxílio de uma micropipeta, $1,0 \mathrm{~mL}$ da amostra para um tubo de ensaio contendo $9,0 \mathrm{~mL}$ de Solução Salina Peptonada (SSP) a $0,1 \%$ de forma a adquirir uma diluição de $10^{-1}$. Posteriormente, foi retirado $1,0 \mathrm{~mL}$ desta diluição $10^{-1}$, transferindo-a para outro tubo contendo $9,0 \mathrm{~mL}$ de SSP a $0,1 \%$, obtendo assim a diluição de $10^{-2}$. Repetiu-se o mesmo método com a diluição de $10^{-2}$, obtendo-se assim a diluição de $10^{-3}$.

Para cada amostra corresponderam três séries de três tubos contendo Caldo Lauril Sulfato Triptose (LST), para os quais foi transferido 1,0 mL, com o auxílio de uma micropipeta, de cada diluição de SSP 
correspondente e incubados de $35^{\circ} \mathrm{C} / 24 \mathrm{~h}$, reincubando os negativos por mais $24 \mathrm{~h}$. Os tubos de LST que apresentaram formação de gás no interior do tubo do Durhan e turvação do meio foram considerados positivos, sendo assim, foi dado prosseguimento à próxima etapa.

De cada tubo de Caldo LST positivo, com crescimento e produção de gás, foi transferido, por meio de alça bacteriológica, uma alíquota para os tubos correspondentes contendo Caldo Verde Brilhante Lactose Bile (VBBL), para contagem de coliformes totais, incubandoos a uma temperatura de $35^{\circ} \mathrm{C}$ por $24-48 \mathrm{~h}$; e uma alíquota para tubos correspondentes contendo Caldo para Escherichia coli (EC), para contagem de coliformes termotolerantes, que foram incubandos em banho-maria com circulação de água a $44,5^{\circ} \mathrm{C}$ por $24-48$ h. A partir dos tubos positivos, com turvação e que produziram gás no Caldo VBBL e Caldo EC, foram feitas as anotações para as verificações dos NMP na tabela de Hoskins, para coliformes totais e termotolerantes, respectivamente, de acordo com Silva et al. (2017).

Os testes bioquímicos utilizados para a identificação de espécies de bactérias pertencentes ao grupo dos coliformes termotolerantes, pertencentes a família Enterobacteriaceae, são conhecidos como IMViC - Indol; Vermelho de Metila (VM); Voges-Proskauer (VP) e Citrato de Simmons.
De cada tubo de Caldo EC positivo com turvação e produção de gás, estriouse uma alçada em placa de Petri contendo Ágar Eosina Azul de Metileno (EMB) e incubou-se a $35^{\circ} \mathrm{C}$ por 24 horas. Após a incubação observou-se 0 desenvolvimento de UFC (Unidades Formadoras de Colônias) verdes nucleadas com centro preto, com ou sem brilho metálico, típicas e sugestivas para Escherichia coli.

Havendo colônias típicas, transferiramse dez colônias bem isoladas para tubos de ensaio contendo Ágar Nutriente (AN) incubando-os a $35{ }^{\circ} \mathrm{C}$ por 24 horas. A partir da cultura pura em AN foram inoculados em diferentes meios de cultura para realização das provas bioquímicas: Ágar Citrato de Simmons, Caldo Triptona, Caldo Vermelho de Metila (VM) e Voges Proskauer (VP), seguindo a técnica descrita por Silva et al. (2017).

Para a contagem de estafilococos foi transferido, com o auxílio da micropipeta, $0,1 \mathrm{~mL}$ de cada diluição $\left(10^{-1}, 10^{-2}, 10^{-3}\right)$ para placas de Petri contendo meio de cultura Ágar Baird Parker (ABP) e com o auxílio da alça de Drigalski (técnica spread plate) foi realizado 0 espalhamento da alíquota até completa absorção pelo meio de cultura.

Em seguida as placas foram incubadas a $35^{\circ} \mathrm{C}$ por 24 horas. Após esse período foram realizadas as visualizações e logo em seguida, com auxílio do contador de colônia, foi possível realizar a contagem 
de UFC típicas (placas com intervalo de 20-200 UFC), colônias negras com halo ao redor, confirmando-se com coloração de Gram. As provas bioquímicas de identificação de Staphylococcus coagulase positiva foram: teste de coagulase e teste de catalase.

Foram realizadas as seguintes análises físico-químicas com as amostras de leite cru: $\mathrm{pH}$, densidade, acidez Dornic, teste do alizarol e presença de amido, de acordo com o Instituto Adolfo Lutz (IAL, 2008).

Para a verificação do potencial hidrogeniônico foi utilizado o medidor de $\mathrm{pH}$ (pHmetro Marconi ${ }^{\circledR}$ MA-522) em cerca de $70 \mathrm{~mL}$ de cada amostra de leite coletado.

Para avaliar a acidez Dornic foram transferidos $10 \mathrm{~mL}$ da amostra para um Becker e adicionou-se de quatro a cinco gotas da solução de fenolftaleína a $1 \%$. Em seguida foi titulada com o auxílio de uma bureta a solução Dornic $(\mathrm{NaOH} 0,11$ $\mathrm{N})$ até aparecimento de coloração rósea persistente por aproximadamente 30 segundos. Foi verificado o volume de solução utilizada, sendo que para cada $0,1 \mathrm{~mL}$ titulado corresponde a $1^{\circ} \mathrm{D}$ e cada grau Dornic corresponde a 0,01\% (m/v) ou 0,1 g/L de ácido lático. A normalidade é entre 14 e $18^{\circ} \mathrm{D}$ (BRASIL, 2018a).

Ao mensurar a densidade do leite cru, foram transferidos $500 \mathrm{~mL}$ da amostra para uma proveta, evitando incorporação de ar e formação de espuma. Logo após foi colocado o termolactodensímetro $\left(\right.$ Docina $\left.^{\circledR}\right)$ perfeitamente limpo e seco na amostra. Foi aguardado até que ele flutuasse sem encostar a parede da proveta e estabilizasse para realização da leitura da densidade e da temperatura. Em seguida foi observada a densidade aproximada (tomada a $15^{\circ} \mathrm{C}$ ), elevando assim, cuidadosamente 0 termolactodensímetro e enxugando sua haste com papel absorvente (papel toalha) e retornando-o aparelho à posição anteriormente observada deixando-o em repouso por um a dois minutos. Foi realizada a leitura da densidade na cúspide do menisco. A normalidade deve ser entre 1,028-1,034 g/mL (BRASIL, 2018a).

No teste do alizarol foi necessário misturar, em um tubo de ensaio, $10 \mathrm{~mL}$ da solução de alizarol e $10 \mathrm{~mL}$ da amostra do leite cru. Após homogeneização foi observado a coloração (determinação colorimétrica referente à mudança de $\mathrm{pH}$ ) e aspecto (formação de grumos, flocos ou coágulos grandes). Se a cor observada fosse vermelho-tijolo com aspecto das paredes do tubo de ensaio sem grumos ou com uma ligeira precipitação, com poucos grumos muito finos, interpretavase o resultado considerando-se a amostra de leite com padrão normal de acidez e estabilidade ao álcool (TRONCO, 1997).

Se a cor encontrada for mais clara, passando para uma tonalidade entre o marrom claro e amarelo, o leite apresenta- 
se ácido (na acidez elevada ou no colostro, a coloração é amarela, com coagulação forte). Se a coloração encontrada for lilás a violeta o leite apresenta-se com reação alcalina (mamites, presença de neutralizantes, fraude por adição de água).

$\mathrm{Na}$ pesquisa de presença de amido foi colocado $10 \mathrm{~mL}$ da amostra do leite cru aquecido em um tubo de ensaio e depois adicionado cinco gotas de lugol. Foi observada a formação de um anel azul no tubo indicando resultado positivo ou um anel de cor amarela indicando resultado negativo.

$\mathrm{Na}$ segunda e quarta coletas das amostras de leite cru escolheu-se, aleatoriamente, uma amostra para serem realizadas as análises microbiológica e físico-química também após a fervura, durante cinco minutos, contando os cinco minutos a partir do início da fervura da amostra.

\section{RESULTADOS E DISCUSSÃO}

Das 12 (100\%) amostras analisadas, todas apresentaram contaminação por coliformes totais e dez (83,33\%) amostras apresentaram contaminação por coliformes termotolerantes (Tabela 1).

Apesar de não haver padrão em legislação para leite cru refrigerado, os achados da presente pesquisa são relevantes, uma vez que os microrganismos do grupo coliformes são considerados indicadores de condições higiênico-sanitárias. Ademais, na legislação vigente é preconizado o padrão de $10 \mathrm{UFC} / \mathrm{mL}$ para contagem de Enterobacteriaceae para 0 leite pasteurizado destinado ao consumo humano (BRASIL, 2018a; 2018b; 2019). Os resultados do presente trabalho são preocupantes, visto que os coliformes são pertencentes a família Enterobacteriaceae e os valores encontrados foram superiores ao padrão considerado em legislação para um produto inócuo.

TABELA 1. Enumeração de coliformes totais e termotolerantes $(\mathrm{NMP} / \mathrm{mL})$ e contagem de estafilococos (UFC/mL) em amostras de leite cru comercializados informalmente no município de Ibirapuã-BA.

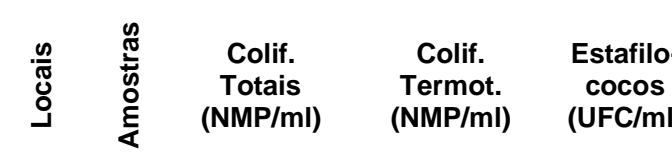

\begin{tabular}{|c|c|c|c|c|}
\hline \multirow{4}{*}{ 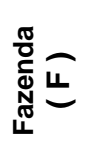 } & 1 & $1,1 \times 10^{3}$ & $1,1 \times 10^{3}$ & $1,6 \times 10^{4}$ \\
\hline & 2 & $1,1 \times 10^{3}$ & $3,5 \times 10^{1}$ & $1,3 \times 10^{4}$ \\
\hline & 3 & $1,1 \times 10^{3}$ & $2,1 \times 10^{2}$ & $7,9 \times 10^{3}$ \\
\hline & 4 & $3,5 \times 10^{1}$ & $2,1 \times 10^{1}$ & $4,6 \times 10^{4}$ \\
\hline \multirow{4}{*}{ 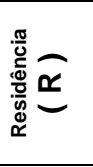 } & 5 & $3,6 \times 10^{1}$ & Ausente & Ausente \\
\hline & 6 & $1,5 \times 10^{1}$ & $1,1 \times 10^{1}$ & $1,5 \times 10^{3}$ \\
\hline & 7 & $2,1 \times 10^{2}$ & $1,1 \times 10^{2}$ & $2,8 \times 10^{4}$ \\
\hline & 8 & $1,1 \times 10^{3}$ & Ausente & $7,6 \times 10^{3}$ \\
\hline \multirow{4}{*}{ 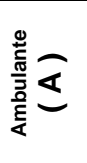 } & 9 & $1,1 \times 10^{3}$ & $1,1 \times 10^{3}$ & $1,8 \times 10^{5}$ \\
\hline & 10 & $1,1 \times 10^{3}$ & $1,1 \times 10^{3}$ & $1,6 \times 10^{5}$ \\
\hline & 11 & $3,5 \times 10^{1}$ & $2,0 \times 10^{1}$ & $8,1 \times 10^{4}$ \\
\hline & 12 & $1,1 \times 10^{3}$ & $1,5 \times 10^{2}$ & $3,6 \times 10^{5}$ \\
\hline \multicolumn{2}{|c|}{ Padrões§ } & $\begin{array}{c}{ }^{*} 1,0 \times 10^{1} \\
{ }^{*}<1,0 \times 10^{0}\end{array}$ & $\begin{array}{c}{ }^{*} 1,0 \times 10^{1} \\
{ }^{*}<1,0 \times 10^{0}\end{array}$ & Não há \\
\hline
\end{tabular}

Em relação aos locais de coletas, todas as amostras coletadas na Fazenda e do Ambulante encontraram-se contaminadas por coliformes totais e termotolerantes, variando entre $20 \mathrm{NMP} / \mathrm{mL}$ e 1.100 $\mathrm{NMP} / \mathrm{mL}$. Das amostras coletadas na 
Residência, que fazia comércio de leite cru, todas apresentaram contaminação por coliformes totais, com variação de 15 $\mathrm{NMP} / \mathrm{mL}$ a $1.100 \mathrm{NMP} / \mathrm{mL}$. Mas as mesmas amostras, duas (50\%) apresentaram presença de coliformes termotolerantes $(11 \mathrm{NMP} / \mathrm{mL}$ a 1.100 $\mathrm{NMP} / \mathrm{mL})$.

Em análises microbiológicas de amostras do leite cru, comercializado no município de Teixeira de Freitas-BA, realizadas por Romeiro et al. (2016) apresentaram treze (65\%) amostras contaminadas por coliformes totais e quatro $(20 \%)$ por coliformes termotolerantes. Enquanto que as análises das amostras de leite fervido, todas (100\%) apresentaram-se livres de coliformes totais e termotolerantes.

Semelhante aos resultados obtidos na pesquisa desse trabalho, Maciel et al. (2008) avaliaram 30 amostras de leite cru obtidas em três pontos de venda no município de Itapetinga-BA e verificaram que todas as amostras estavam contaminadas com coliformes totais e coliformes termotolerantes de $1,5 \times 10^{3} \mathrm{a}$ $2,4 \times 10^{5}$ e de $1,5 \times 10^{3}$ a $9,3 \times 10^{4} \mathrm{NMP} / \mathrm{mL}$, respectivamente.

Em pesquisa realizada por Costa et al. (2020), que realizaram análises de coliformes totais e termotolerantes de leite cru comercializado informalmente na cidade de Murici-AL, as dez amostras analisadas mostraram que $100 \%$ não apresentaram condições higiênicosanitárias satisfatórias.

Catão e Ceballos (2001) analisaram 45 amostras de leite cru no estado da Paraíba e constataram que todas as amostras apresentaram elevada incidência de coliformes a $35^{\circ} \mathrm{C}$, coliformes temotolerantes e E. coli, o que comprova a elevada contaminação da matéria-prima. Tebaldi et al. (2008) verificaram que $31,25 \%$ das amostras avaliadas apresentaram contagem de coliformes termotolerantes acima de $10^{3} \mathrm{NMP} / \mathrm{mL}$.

Segundo Nero et al. (2003), punição e combate à comercialização de leite cru como medidas isoladas de controle não são suficientes para impedir o consumo, sendo fundamental o desenvolvimento de programas de conscientização da população em relação aos riscos que o leite cru pode oferecer.

Sendo assim, de acordo com os resultados obtidos nessa pesquisa, podese afirmar que o leite cru vendido informalmente no município de lbirapuã-BA é impróprio para o consumo humano, uma vez que há contaminação por coliformes totais e termotolerantes, comprometendo a inocuidade do produto e ratificando a problemática para saúde pública referente ao hábito do consumo de leite cru.

Em relação aos possíveis gêneros e espécies da família Enterobacteriaceae encontrados no leite cru, os resultados obtidos são sugestivos para os seguintes microrganismos: Enterobacter spp., Hafnia 
spp., Citrobacter spp./Salmonella spp., Klebsiella spp., Escherichia coli, Serratia liquefaciens, Yersinia enterocolitica, Providencia spp. e Hafnia alvei (Tabela 2).

Bueno et al. (2006), ao fazerem pesquisa em leite pasteurizado produzido e comercializado na região sul do Rio Grande do Sul, evidenciaram uma (2,9\%) amostra com presença de Salmonella spp. Foi encontrado também duas $(5,7 \%)$ com coliformes termotolerantes. Tal achado demonstra que a qualidade insatisfatória da matéria prima pode influenciar na eficiência do tratamento térmico e que mesmo fazendo-se uso de barreiras tecnológicas não se deve desprezar as boas práticas higiênicas de produção.

\begin{tabular}{cc}
$\begin{array}{c}\text { TABELA 2 - Possíveis gêneros e espécies da } \\
\text { família Enterobacteriaceae, encontrados no } \\
\text { leite cru comercializado informalmente no } \\
\text { município de lbirapuã-BA, identificados a } \\
\text { partir dos testes IMViC }\end{array}$ \\
\begin{tabular}{cc}
\multicolumn{2}{c}{ Frequência } \\
n (\%)
\end{tabular} & $\begin{array}{c}\text { Possíveis gêneros } \\
\text { e/ou espécies }\end{array}$ \\
\hline $63(52,29 \%)$ & Enterobacter \\
$7(5,81 \%)$ & Hafnia \\
$3(2,49 \%)$ & Citrobacter / Salmonella \\
$3(2,49 \%)$ & Klebsiella \\
$3(2,49 \%$ & Escherichia coli \\
$1(0,83 \%)$ & Serratia liquefaciens \\
$1(0,83 \%)$ & Yersinia enterocolitica \\
$1(0,83 \%)$ & Providencia \\
$1(0,83 \%)$ & Hafnia alvei \\
\hline $\mathbf{8 3}(\mathbf{1 0 0} \%)$ & Familia Enterobacteriaceae
\end{tabular}

Padilha et al. (2001) verificaram, em suas pesquisas com leite tipo $\mathrm{C}$, a presença de microrganismos dos gêneros Enterobacter, Citrobacter, Erwinia, Klebsiella, Serratia, Pseudomonas, Aeromonas, Bacillus e Salmonella. A existência dessas bactérias fora do padrão de qualidade estabelecida pelas normativas atuais indica que o consumo do leite contaminado é preocupante, uma vez que podem causar toxinfecção alimentar.

Em relação aos resultados da contagem de estafilococos (UFC/mL), das 12 (100\%) amostras analisadas, 11 (91,67\%) apresentaram estafilococos com enumeração variando entre 1.500 UFC/mL a $360.000 \mathrm{UFC} / \mathrm{mL}$; enquanto que apenas uma (8,33\%) teve ausência de estafilococos (Tabela 1).

Não há um padrão para enumeração de estafilococos para o leite cru, porém, isso não significa que o leite cru possa ser consumido caso este esteja contaminado por tal microrganismo, já que a presença desta bactéria no leite pode trazer risco de intoxicação alimentar, mesmo que o leite seja fervido, pois a toxina sintetizada pelos estafilococos são termorresistentes. Estafilococos no leite é indicativo de condições higiênicas insatisfatórias, além de ser preocupante pois é um dos agentes etiológicos causadores da mastite. O microganismo em contagens superiores a $10^{5} \mathrm{UFC} / \mathrm{mL}$ torna-se ainda mais preocupante pela capacidade de sintetizar enterotoxinas e ocasionar danos à saúde do consumidor.

Rosec et al. (1997) analisaram que a presença desse microrganismo também pode ser devida às condições higiênicas insatisfatórias dos locais onde foram feitas as ordenhas, dos latões usados no transporte e dos manipuladores. No 
trabalho de Murphy (1997) relatou que contagens de coliformes totais acima de 10 $\mathrm{NMP} / \mathrm{mL}$, indicam deficiências de higiene no processo de obtenção do leite.

Em pesquisa realizada por Romeiro et al. (2016), na cidade de Teixeira de Freitas$B A$, foi verificada que a maior contagem de estafilococos apresentou $6,1 \times 10^{5} \mathrm{UFC} / \mathrm{mL}$. Diferente dos resultados que foi apresentado nesse trabalho, com maior contagem de estafilococos na amostra 11 coletada de um ambulante com $8,1 \times 10^{4}$ $\mathrm{UFC} / \mathrm{mL}$.

Nos testes de $\mathrm{pH}$, acidez de Dornic, alizarol e amido, das 12 (100\%) amostras, seis (50\%) apresentavam algum tipo de alteração físico-química, sendo cinco $(41,67 \%)$ amostras com alterações de pH e uma $(8,33 \%)$ amostra do leite cru fora do padrão exigido no teste de densidade. Acerca dos resultados obtidos neste trabalho sobre as análises físico-químicas do leite cru, observou-se que a densidade variou de $1.029,6$ a $1.036,0 \mathrm{~g} / \mathrm{mL}$. Os resultados desse trabalho para alizarol foram normais em todas as 12 (100\%) amostras. Também não houve adição de amido nas amostras analisadas de leite cru (Tabela 3).

Nascimento et al. (1995), analisando as características do leite fluido consumido em Belém-PA, obtiveram irregularidades em relação e densidade. Segundo Behmer (1987), o amido, o açúcar e a urina são utilizados criminosamente para encobrir aguagem do leite, aumentando a densidade.

A partir dos resultados das pesquisas obtidos de acordo com a análise fisícoquímica nesse trabalho, pode-se verificar que o $\mathrm{pH}$ variou de 6,10 a 7,96. Paula et al. (2010) realizaram análises físico-químicas em leite cru, provenientes de propriedades leiteiras da região Sul Fluminense e foi constatado que $100 \%$ das amostras analisadas apresentaram $\mathrm{pH}$ dentro do recomendado. A avaliação da acidez e do pH são parâmetros importantes, uma vez que podem ser um indicador da qualidade sanitária e estabilidade térmica do leite.

TABELA 3. Resultados dos testes físico-químicos do leite cru comercializado informalmente no munícipio de Ibirapuã-BA.

\begin{tabular}{ccccccc}
\hline Locais & Amostras & $\mathbf{p H}$ & $\begin{array}{c}\text { Densidade } \\
\mathbf{( g / m L})\end{array}$ & $\begin{array}{c}\text { Acidez } \\
\text { Dornic } \\
\left({ }^{\circ} \mathbf{D}\right)\end{array}$ & $\begin{array}{c}\text { Teste do } \\
\text { Alizarol }\end{array}$ & Amido \\
\hline $\begin{array}{c}\text { Fazenda } \\
\text { ( F ) }\end{array}$ & $\mathbf{1}$ & $\mathbf{6 , 1}$ & $1.030,2$ & 15 & Normal & Ausente \\
& $\mathbf{2}$ & 6,7 & $1.030,6$ & 17 & Normal & Ausente \\
& $\mathbf{3}$ & $\mathbf{7 , 9}$ & $1.030,4$ & 16 & Normal & Ausente \\
Residência & $\mathbf{4}$ & 6,6 & $1.029,6$ & 17 & Normal & Ausente \\
( R ) & $\mathbf{5}$ & 6,6 & $1.032,0$ & 18 & Normal & Ausente \\
& $\mathbf{6}$ & 6,6 & $1.031,8$ & 17 & Normal & Ausente \\
Ambulante & $\mathbf{7}$ & $\mathbf{8 , 0}$ & $1.031,2$ & 15 & Normal & Ausente \\
( A ) & $\mathbf{8}$ & 6,6 & $1.030,4$ & 18 & Normal & Ausente \\
\hline
\end{tabular}




\begin{tabular}{|c|c|c|c|c|c|}
\hline 12 & 6,6 & $1.030,4$ & 17 & Normal & Ausente \\
\hline Padrão* & $6,6-6,7 \S$ & 1.028-1.034* & $14-18^{*}$ & Normal* & Ausente* $^{*}$ \\
\hline
\end{tabular}

Ainda em relação ao $\mathrm{pH}$, Cortez e Cortez (2008) afirmam que $\mathrm{o} \mathrm{pH}$ do leite deve variar entre 6,5 e 6,7. Sendo assim, das 12 amostras analisadas, quatro $(33,33 \%)$ encontravam-se fora da margem desejável (Tabela 3).

Mendes et al. (2010) observaram que $100 \%$ das amostras de leite cru obtidas no município de Mossoró-RN apresentavamse em acordo com o recomendado pela legislação para a prova do alizarol. Das amostras analisadas, 100\% estavam de acordo com a legislação (BRASIL, 2018a; 2018b).

Quanto ao resultado da pesquisa desse trabalho, pode-se observar que das 12 (100\%) amostras não apresentaram amido em sua composição. Seguindo o mesmo resultado por Paula et al. (2010) examinando o leite cru refrigerado proveniente da região Sul Fluminense, verificaram que nas amostras analisadas não foi observado a presença de amido. Tendo em vista que, a adição de amido no leite é um ato fraudulento, realizado com o objetivo de corrigir a densidade do leite precedido de aguagem (RIBEIRO JÚNIOR et al., 2013).

Ainda sobre as análises físico-químicas, em pesquisa realizada em Teixeira de Freitas-BA por Romeiro et al. (2016), do total de 20 amostras, cinco (25\%) estavam fora do padrão para acidez Dornic, divergindo dos resultados desse trabalho que nenhuma amostra apresentou resultado inferior ou superior ao padrão estabelecido pelas normas atuais.

Comparando-se os resultados destas amostras de leite cru fervido, durante cinco minutos, com as mesmas amostras sem ferver foi possível verificar que após este processo foram eliminados os microrganismos dos grupos de coliformes totais e termotolerantes e também estafilococos. Em relação aos testes físicoquímicos não houve alterações, pois as amostras, após a fervura, continuaram dentro dos padrões estabelecidos (Tabela 4).

Em trabalho realizado por Romeiro et al. (2016), com leite cru fervido após cinco minutos, verificaram que houve diminuição da contaminação por microrganismos do grupo coliformes. Porém, das 20 amostras analisadas, 13 (65\%) amostras ainda se apresentavam com enumeração de coliformes totais acima dos padrões e quatro (20\%) amostras fora dos padrões para coliformes termotolerantes. 
TABELA 4. Comparação dos resultados das análises microbiológica e físico-química de duas amostras de leite cru antes de ferver e após a fervura por cinco minutos.

\begin{tabular}{ccccccc}
\hline \multirow{2}{*}{ A N Á L I S E S } & \multicolumn{2}{c}{ LEITE CRU } & \multicolumn{2}{c}{ LEITE FERVIDO } \\
\cline { 3 - 6 } & & \multicolumn{10}{c}{ A $\mathbf{M}$ O S T R A S } \\
\cline { 3 - 6 } Microbiológica & Coliformes Totais & $1,1 \times 10^{3}$ & $1,1 \times 10^{3}$ & Ausente & Ausente \\
& Col. Termotolerantes & $1,1 \times 10^{3}$ & $1,5 \times 10^{2}$ & Ausente & Ausente \\
& Estafilococos & $1,6 \times 10^{5}$ & $3,6 \times 10^{5}$ & Ausente & Ausente \\
\hline \multirow{2}{*}{ Físico-química } & $\mathbf{p H}$ & 6,6 & 6,5 & 6,6 & 6,7 \\
& Acidez Dornic & $18^{\circ} \mathrm{D}$ & $17^{\circ} \mathrm{D}$ & $18^{\circ} \mathrm{D}$ & $17^{\circ} \mathrm{D}$ \\
& Densidade & $1.029,8$ & $1.030,4$ & $1.030,2$ & $1.030,2$ \\
& Alizarol & Normal & Normal & Normal & Normal \\
& Amido & Ausente & Ausente & Ausente & Ausente \\
\hline
\end{tabular}

Torna-se importante ressaltar que a comercialização de leite cru é ilegal e vai contra as normas de segurança alimentar. Além disso, o consumo de leite cru acaba sendo um risco à Saúde Pública pela possível presença de microrganismos patogênicos neste produto. Por conseguinte, tais resultados demonstram a importância do processamento do leite cru, pois mesmo com o processo de fervura do leite cru, nem sempre ocorre a eliminação total de microrganismos contaminantes no produto. Destaca-se, assim, a importância do tratamento do leite pelo calor com controle dos binômios tempo $X$ temperatura, respeitando a um padrão que comprovadamente destrua células bacterianas patogênicas e garanta a inocuidade, como por exemplo a pasteurização.

\section{CONCLUSÃO}

O leite cru comercializado, de forma clandestina, no município de Ibirapuã-BA apresentou elevados índices de contaminação por microrganismos patogênicos, tais como coliformes termotolerantes e estafilococos.

Com base nos resultados obtidos no presente estudo conclui-se que há necessidade de se mitigar a venda e 0 consumo de leite cru por representar risco à saúde do consumidor. Além disso, é importante enfatizar a necessidade de esclarecimentos à população sobre os riscos de toxinfecções alimentares devido ao consumo deste leite cru.

\section{REFERÊNCIAS BIBLIOGRÁFICAS}

BEHMER, M. L. A. Tecnologia do Leite: Leite, Queijo, Manteiga, Caseína, logurte, Sorvetes e Instalações: Produção, Industrialização, Análise. 15. ed. São Paulo: Nobel, 1987. 320 p.

BRASIL. Ministério da Agricultura Pecuária e Abastecimento (MAPA). Instrução Normativa $n^{\circ} 76$, de 26 de novembro de 2018. Dispõe sobre a Aprovação dos Regulamentos Técnicos de Produção, Identidade e Qualidade do Leite Tipo A, B e $C$ do Leite Pasteurizado e do Leite Cru 
Refrigerado e o Regulamento técnico da coleta de Leite Cru Refrigerado e seu Transporte a granel. Diário Oficial da União. Brasília, 30 de nov. 2018a. Seção 1, p. 9.

. Ministério da Agricultura Pecuária e Abastecimento (MAPA). Instrução Normativa $n^{\circ} 77$, de 26 de novembro de 2018. Dispõe sobre a Aprovação dos Regulamentos Técnicos de Produção, Identidade e Qualidade do Leite Tipo A, B e C do Leite Pasteurizado e do Leite Cru Refrigerado e o Regulamento técnico da coleta de Leite Cru Refrigerado e seu Transporte a granel. Diário Oficial da União. Brasília, 30 de nov. 2018b. Seção 1, p. 10.

Ministério da Agricultura, Pecuária e Abastecimento (MAPA). Decreto $n^{\circ}$ 9.013 , de 29 de março de 2017. Dispõem sobre a inspeção industrial e sanitária de produtos de origem animal. Diário Oficial da União. Rio de Janeiro, 3 de outubro de 2017.

Ministério da Agricultura, Pecuária e Abastecimento (MAPA). Instrução Normativa $n^{\circ} 60$, de 23 de dezembro de 2019. Estabelece as listas de padrões microbiológicos para alimentos. Diário Oficial da União. Brasília, 26 de dez. 2019. Seção 1, p. 133.

BUENO, F. M.; JANTZEN, M. M.; LIMA, A. S.; PIMENTA, K.; SILVA, W. P. Leite pasteurizado produzido e comercializado na região sul do Rio Grande do Sul: Avaliação da qualidade microbiológica.

Revista Higiene Alimentar. v. 21, n. 150. p. 220, 2006.

CATÃO, R. M. R; CEBALLOS, B. S. O. Listeria spp., coliformes totais, coliformes fecais e Escherichia coli no leite cru e pasteurizado de uma indústria de laticínios, no estado da Paraíba (BR). Ciência e Tecnologia de Alimentos, v. 21, n. 3, p. 281-287, 2001.

CORTEZ, M. A. S.; CORTEZ, N. M. S. Qualidade do Leite. Boas Práticas Agropecuárias e Ordenha Higiênica. Niterói: EdUFF. 2008. 77 p.
COSTA, C. A. C. B.; SANTOS, J. V. L.; MELO, E. A. P.; FREITAS, A. J. D.; SOUSA, J. S.; FREITAS, J. M. D.; FREITAS, J. D. Caracterização da qualidade microbiológica do leite cru comercializado informalmente na cidade de Murici, Alagoas. Brazilian Journal of Deveçopment, v. 6, n. 2, p. 7.026-7.035, 2020.

FERRÃO, S. P. B.; SILVA, A. G.; FERRÃO, I. S.; BRITO, A. R.; COUTO, F. M.; SANTOS, S. M. A. Leite informal: uma abordagem qualitativa junto aos consumidores de Itapetinga, Bahia. Revista do Instituto de Laticínios Cândido Tostes, v. 58, n. 333, p. 245- 247, 2003.

FRANCO, B. D. G. M.; LANDGRAF, M. Microbiologia dos Alimentos. São Paulo: Atheneu, 2005.

IAL (Instituto Adolfo Lutz). Métodos Físico-Químicos para Análise de Alimentos. São Paulo: Instituto Adolfo Lutz. 2008, 1.020 p.

IBGE (Instituto Brasileiro de Geografia e Estatística). Cidades. [online]. Disponível em:

$<$ https://cidades.ibge.gov.br/brasil/ba/ibira pua/panorama>. Acesso em: 20 de maio de 2020.

IBIRAPUÃ. Cidade-Brasil. [online]. Disponível em: <https://www.cidadebrasil.com.br/municipio-ibirapua.html>.

Acesso em: 20 de maio de 2020.

MACIEL, J. F.; CARVALHO, E. A.; SANTOS, L. S.; ARAÚJO, J. B.; NUNES, V.S. Qualidade microbiológica de leite cru comercializado em Itapetinga-BA. Revista Brasileira de Saúde e Produção Animal, v. 9, n. 3, p. 443-448, 2008.

MENDES, C. G.; SAKAMOTO, S. M.; SILVA, J. B. A.; JÁCOME, C. G. M.; LEITE, A. I. Análise físico-química e pesquisa de fraude no leite informal comercializado no município de Mossoró, RN. Ciência Animal Brasileira, v. 11, n. 2, p. 349-356, 2010.

MURPHY, S. Raw milk bacteria tests: standard plate count, preliminary incubation counts, lab pasteurized count, 
and coliform count. What do they mean for your farm? p. 34-42. In: National Mastitis Council Regional Meeting. Syracuse. Proceedings Syracuse. 1997.

NASCIMENTO, J. A. C.; SILVA, R. A. G.; FREITAS, J. A. Características do leite fluido consumido em Belém, Pará. Arquivo Brasileiro de Medicina Veterinária e Zootecnia, v. 47, n. 3, p. 435-445, 1995.

NERO, L. A.; MATTOS, M. R.; BELOTI, V.; BARROS, M. A. F.; NETTO, D. P.; PINTO, J. P. A. N.; ANDRADE, N. J.; SILVA, W. P.; FRANCO, B. D. G. M. Hazards in nonpasteurized milk on retail sale in Brazil: prevalence of Salmonella spp., Listeria monocytogenes and chemical residues. Brazilian Journal of Microbiology, v. 35, n. 3, p. 211-215, 2004.

NERO, L. A.; MAZIERO, D.; BEZERRA, M. M. S. Hábitos alimentares do consumidor de leite cru de Campo Mourão, PR. Semina: Ciências Agrárias, v. 24, n. 1, p. 21-26, 2003.

OLIVEIRA, A. J.; CARUSO, J. G. B. Leite: Obtenção e Qualidade do Produto Fluido e Derivados. Piracicaba: FEALQ, 1996.

PADILHA, M. R. F.; FERNANDES, Z. F.; LEAL, T. C. A.; LEAL, N. C.; ALMEIDA, A. M. P. Pesquisa de bactérias patogênicas em leite pasteurizado tipo C comercializado na cidade do Recife, Pernambuco, Brasil. Revista da Sociedade Brasileira de Medicina Tropical, v. 34, n. 2, p. 167-171, 2001.

PAULA, F. P. D; CARDOSO, C. E.; RANGEL, M. A. C. Análise físico-química do leite cru refrigerado proveniente das propriedades leiteiras da região sul fluminense. Revista Eletrônica TECCEN, v. 3, n. 4, p. 7-18, 2010.

RIBEIRO JÚNIOR, J. C.; BELOTI, V.; SILVA, L. C. C.; TAMANINI, R. Avaliação da qualidade microbiológica e físicoquímica do leite cru refrigerado produzido na região de Ivaiporã, Paraná. Revista do Instituto de Laticínios Cândido Tostes, v. 68, n. 392, p. 5-11, 2013.

ROMEIRO, S. S.; MEIRA, I. A.; SOUSA, L. F.; FORTUNA, J. L. Análise bacteriológica e físico-química de leite cru comercializado informalmente em Teixeira de Freitas-BA. Ciência \& Tecnologia, v. 8, Número Especial, 2016.

ROSA, L. S.; QUEIROZ, M. I. Avaliação da qualidade do leite cru e resfriado mediante a aplicação de princípios do APPCC. Ciência e Tecnologia de Alimentos, v. 27, n. 2, p. 422-430, 2007.

ROSEC, J. P.; GUIRAUD, J. P.; DALET, C.; RICHARD, N. Enterotoxin production by Staplylococcus isolated from foods in France. International Journal of Food Microbiology, v. 35, p. 213-221, 1997.

SILVA, C. F. Viração: o comércio informal dos vendedores ambulantes. Saídas de Emergência: Ganhar/Perder a Vida na Periferia de São Paulo. São Paulo: Boitempo. 2011.

SILVA, N.; JUNQUEIRA, V. C. A.; SILVEIRA, N.; TANIWAKI, M. H.; GOMES, R. A. R.; OKAZAKI, M. M. Manual de Métodos de Análises Microbiológicas de Alimentos. 5 ed. São Paulo: Blucher. 2017.

TEBALDI, V. M. R.; OLIVEIRA, T. L. C.; BOARI, C. A.; PICCOLI, R. H. Isolamento de coliformes, estafilococos e enterococos de leite cru provenientes de tanques de refrigeração por expansão comunitários: identificação, ação lipolítica e proteolítica. Ciência e Tecnologia de Alimentos, v.28, n.3, p.753-760, 2008.

TELLES, V. S. Jogos de poder nas dobras do legal e ilegal: anotações de um percurso de pesquisa. p. 27-55. In: AZAIS, C.; KESSLER, G.; TELLES, V. S. Ilegalismos, Cidade e Política. Belo Horizonte: Finos Traços. 2012.

TRONCO, V. M. Manual para Inspeção da Qualidade do Leite. Santa Maria: UFSM. 1997, $166 \mathrm{p}$. 